\title{
Studi Pengaruh Temperatur Reaktor Gasifikasi Terhadap Fuel Conversion Rate Gasifikasi Dual Reactor Fluidized Bed
}

\author{
( Wayan Arya Darma ${ }^{1)^{*}}$, I Nyoman Suprapta Winaya ${ }^{2)}$, I Ketut Gede Wirawan ${ }^{2)}$ \\ ${ }^{1)}$ Program Studi Magister Teknik Mesin, Fakultas Teknik, Universitas Udayana \\ Kampus Sudirman, Bali 80232 \\ Email: s4d4m ajus@yahoo.com \\ 2) Jurusan Teknik Mesin, Fakultas Teknik, Universitas Udayana \\ Kampus Bukit Jimbaran, Bali 80362 \\ Email: ins.winaya@unud.ac.id , ikgwirawan@unud.ac.id \\ doi: https://doi.org/10.24843/METTEK.2018.v04.102.p01
}

\begin{abstract}
Abstrak
Terjadinya krisis energi mendorong pemerintah untuk melakukan upaya pengembangan bahan bakar alternatif, yang berasal dari sumber daya energi terbarukan, salah satunya adalah biomassa. Pada penelitian ini proses konversi energi biomassa dilakukan menggunakan teknologi dual reactor fluidized bed. Bahan bakar biomassa yang digunakan adalah sekam padi dan pasir silika digunakan sebagai material bed nya. Temperatur pada reaktor gasifikasi diatur antara $600-700^{\circ} \mathrm{C}$ dan temperatur pada reaktor pembakaran konstan pada $700^{\circ} \mathrm{C}$. Hasil penelitian menunjukkan peningkatan temperatur pada reaktor gasifikasi berpengaruh terhadap meningkatnya fuel conversion rate pada proses gasifikasi.
\end{abstract}

Kata kunci: Dual reactor fluidized bed, temperatur, carbon efficiency

Abstract

The occurrence of an energy crisis encourages the government to make efforts to develop alternative fuels, which come from renewable energy resources, one of which is biomass. In this study, the biomass energy conversion process was carried out using a dual reactor fluidized bed technology. The biomass fuel used is rice husk and silica sand is used as bed material. The temperature in the gasification reactor is set between 600-7000C and the temperature in the combustion reactor is constant at 7000C. The results showed that the increase in temperature in the gasification reactor had an effect on increasing carbon efficiency in the gasification process.

Keywords: Dual reactor fluidized bed, temperature, carbon efficiency

\section{PENDAHULUAN}

Peningkatan konsumsi energi muncul seiring dengan pertumbuhan ekonomi dan pertambahan penduduk. Terjadinya krisis energi mendorong pemerintah untuk melakukan upaya pengembangan bahan bakar alternatif salah satunya adalah biomassa. Biomassa terbentuk dari spesies hidup seperti tumbuhan dan hewan yang hidup sekarang ataupun yang masih hidup beberapa waktu yang lalu [1]. Gasifikasi merupakan salah satu teknologi yang digunakan untuk mengkonversi bahan bakar biomassa menjadi gas mampu bakar. Teknologi gasifikasi yang sedang dikembangkan saat ini adalah dual reactor fluidized bed, dimana pada teknologi ini menggunakan dua reaktor yaitu reaktor pembakaran dan reaktor gasifikasi. Pada reaktor pembakaran terjadi proses pembakaran yang menghasilkan panas (reaksi eksotermik) dan panas hasil proses pembakaran digunakan untuk proses endotermik pada reaktor

Penulis korespondensi, HP: 081806455848

Email: s4d4m ajus@yahoo.com 
gasifikasi. Material bed sebagai penghantar panas bersirkulasi dari reaktor pembakaran menuju reaktor gasifikasi. Peningkatan temperatur udara pada gasifikasi dual reactor fluidized bed mengakibatkan laju reaksi gasifikasi meningkat dan menghasilkan komposisi kandungan $\mathrm{CO}$ yang tinggi serta efisiensi yang tinggi [2]. Panas yang dihasilkan akibat proses oksidasi pada reaktor pembakaran harus cukup untuk memenuhi kebutuhan energi panas dari reaksi gasifikasi [3]. Untuk reaksi reversibel eksotermik, peningkatan temperatur dapat meningkatkan laju reaksi tetapi keseimbangan konversi reaktan menjadi produk menjadi kurang menguntungkan. Reaksi endotermik yang terjadi pada reaktor gasifikasi bersifat kinetik dan termodinamik yang meningkat pada temperatur tinggi [4] sehingga diperlukan penambahan temperatur pada reaktor gasifikasi. Oleh karena itu dilakukan penelitian mengenai pengaruh temperatur pada reaktor gasifikasi terhadap fuel conversion rate bahan bakar biomassa.

\section{METODE}

\subsection{Skematik Unit Dual Reactor Fluidized Bed}

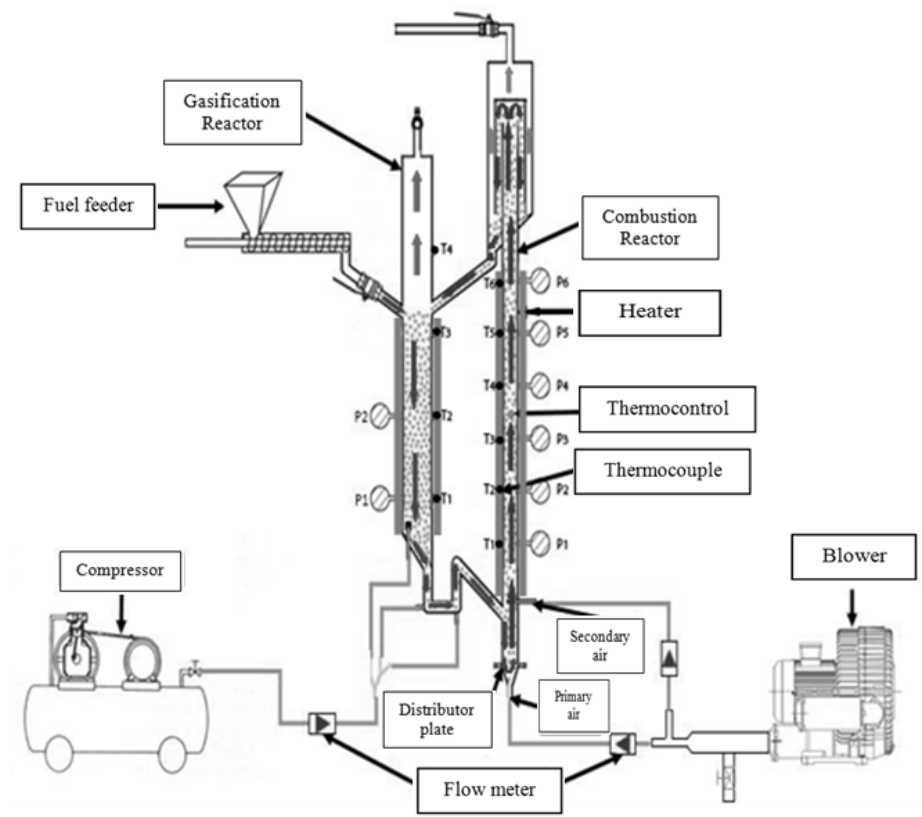

Gambar 1. Skematik unit dual reactor fluidized bed

Unit dual reactor fluidized bed ini terdiri dari dua reaktor yaitu reaktor gasifikasi dan reaktor pembakaran. Reaktor gasifikasi dan reaktor pembakaran terbuat dari stainless steel schedule 304. Reaktor gasifikasi memiliki ukuran panjang $668 \mathrm{~mm}$ dengan diameter 101.6 $\mathrm{mm}$ sedangkan reaktor pembakaran memiliki ukuran panjang $1111 \mathrm{~mm}$ dengan diameter 50.8 $\mathrm{mm}$. Pada kedua reaktor dipasangi heater. Daya listrik yang diperlukan heater pada reaktor pembakaran adalah 1500 Watt sedangkan pada heater reaktor gasifikasi adalah 2500 Watt. Pemasangan pressure gauge di beberapa titik kedua reaktor berfungsi untuk mengetahui apakah bed material bersirkulasi dengan baik pada reaktor gasifikasi dan pembakaran. Pressure gauge yang dipasang pada reaktor pembakaran berjumlah 6 buah dan pada reaktor gasifikasi berjumlah 2 buah. Pemasangan thermocouple pada kedua reaktor berfungsi untuk mengetahui distribusi temperatur pada reaktor saat heater mulai dinyalakan sampai selesai pengujian. Pada reaktor gasifikasi dipasangi 4 buah thermocouple dan pada reaktor pembakaran dipasangi 6 buah thermocouple. Thermocouple tersebut disambungkan ke data logger kemudian ditampilkan dalam bentuk grafik pada laptop. Temperatur kerja yang diperlukan untuk memanaskan reaktor dapat diatur dan dilihat pada thermocontrol. Terdapat dua thermocontrol masing-masing untuk mengontrol temperatur pada reaktor gasifikasi dan 
reaktor pembakaran.

Pada unit dual reactor fluidized bed terdapat fuel feeder (screw feeder) sebagai tempat untuk memasukkan bed material pasir silika dan biomassa sekam padi ke dalam reaktor gasifikasi. Kompresor berfungsi untuk menyuplai udara bertekanan agar campuran bahan bakar dan bed material dapat bersirkulasi dari reaktor gasifikasi ke reaktor pembakaran. Blower digunakan untuk menyuplai udara ke dalam reaktor pembakaran agar campuran biomassa dan material hamparan pasir silika dapat terangkat kemudian bersirkulasi kembali ke reaktor gasifikasi.

\subsection{Bahan Penelitian}

Biomassa yang digunakan sebagai bahan bakar adalah sekam padi yang sudah berbentuk butiran kecil dengan ukuran yang sama yaitu antara 0.4 sampai $0.5 \mathrm{~mm}$. Bed material yang digunakan adalah pasir silika dengan ukuran yang sama yaitu antara 0.4 sampai $0.5 \mathrm{~mm}$. Analisa proximate dilakukan untuk mengetahui kandungan unsur-unsur dari bahan bakar sekam padi, seperti: moisture (kadar air), ash (abu), fixed carbon (karbon tetap) dan volatile (bahan mudah menguap), sedangkan analisa ultimate dilakukan untuk mengetahui unsur-unsur kimia pada bahan bakar sekam padi seperti: karbon $(\mathrm{C})$, hidrogen $(\mathrm{H})$, oksigen $(\mathrm{O})$, nitrogen $(\mathrm{N})$ dan sulfur $(\mathrm{S})$. Hasil analisa proximate dan ultimate dari sekam padi dapat dilihat pada tabel 1 dan 2. Nilai kalor dari bahan bakar sekam padi dapat diketahui dengan melakukan pengujian bom kalorimeter dan hasilnya dapat dilihat pada tabel 3.

Tabel 1. Hasil analisa proximate biomassa sekam padi

\begin{tabular}{cccccc}
\hline No & $\begin{array}{c}\text { Sampel } \\
\text { bahan bakar }\end{array}$ & $\begin{array}{c}\text { Moisture } \\
(\%)\end{array}$ & $\begin{array}{c}\text { Ash } \\
(\%)\end{array}$ & $\begin{array}{c}\text { Fixed } \\
\text { carbon } \mathbf{( \% )}\end{array}$ & $\begin{array}{c}\text { Volatile } \\
(\%)\end{array}$ \\
\hline 1 & Sekam padi & 22 & 19.15 & 24.18 & 34.67 \\
\hline
\end{tabular}

Tabel 2. Hasil analisa ultimate biomassa sekam padi

\begin{tabular}{ccccccc}
\hline No & $\begin{array}{c}\text { Sampel } \\
\text { bahan bakar }\end{array}$ & $\begin{array}{c}\mathbf{C} \\
(\%)\end{array}$ & $\begin{array}{c}\mathbf{H} \\
\mathbf{( \% )}\end{array}$ & $\begin{array}{c}\mathbf{O} \\
(\mathbf{\%})\end{array}$ & $\begin{array}{c}\mathbf{N} \\
(\mathbf{\%})\end{array}$ & $\begin{array}{c}\mathbf{S} \\
(\mathbf{\%})\end{array}$ \\
\hline 1 & Sekam padi 1 & 34.179 & 3.652 & 32.629 & 0.02593 & 0.00448 \\
2 & Sekam padi 2 & 33.886 & 3.5866 & 32.726 & 0.02449 & 0.00342 \\
& Rata-rata & 34.0325 & 3.6193 & 32.6775 & 0.02521 & 0.00395 \\
\hline
\end{tabular}

Tabel 3. Hasil pengujian bom kalorimeter biomassa sekam padi

\begin{tabular}{|c|c|c|c|c|c|c|c|}
\hline \multirow{2}{*}{$\begin{array}{c}\text { Sampel } \\
\text { bahan bakar }\end{array}$} & \multirow{2}{*}{$\begin{array}{c}\text { Berat } \\
\text { sampel } \\
\text { (gram) }\end{array}$} & \multirow{2}{*}{$\begin{array}{c}\text { Kapasitas } \\
\text { kalor } \\
\left(\mathbf{C a l} /{ }^{0} \mathrm{C}\right)\end{array}$} & \multicolumn{2}{|c|}{ Temperatur } & \multicolumn{3}{|c|}{ Nilai kalor (Qc) } \\
\hline & & & $\begin{array}{c}\mathrm{T} 1 \\
\left({ }^{0} \mathrm{C}\right)\end{array}$ & $\begin{array}{c}\mathrm{T} 2 \\
\left({ }^{0} \mathrm{C}\right)\end{array}$ & $\begin{array}{l}\text { Sampel } \\
\text { (Cal/gr) }\end{array}$ & $\begin{array}{c}\text { Rata-rata } \\
\text { (Cal/gr) }\end{array}$ & $\begin{array}{c}\mathrm{HHV} \\
\mathrm{MJ} / \mathrm{Kg}\end{array}$ \\
\hline Sekam padi & 1 & 2380.558 & 29.38 & 31.93 & 6046.616 & & \\
\hline Sekam padi & 1 & 2380.558 & 28.06 & 29.92 & 4427.837 & & $y$ \\
\hline
\end{tabular}

\subsection{Prosedur Penelitian}

Melalui fuel feeder pasir silika sebagai bed material dimasukkan kedalam reaktor gasifikasi dengan jumlah 600 gram. Heater pada reaktor gasifikasi dan reaktor pembakaran dinyalakan sampai temperatur pada reaktor pembakaran mencapai $700^{\circ} \mathrm{C}$ dan temperatur pada reaktor gasifikasi antara $600-700^{\circ} \mathrm{C}$. Temperatur kerja yang diperlukan untuk memanaskan reaktor dapat diatur dan dilihat pada thermocontrol. Terdapat dua thermocontrol masingmasing untuk mengontrol temperatur pada reaktor gasifikasi dan reaktor pembakaran. 
Hidupkan kompresor untuk mensirkulasikan bed material ke reaktor pembakaran dengan volume aliran 22.7 liter/min. Aliran udara yang dialirkan melalui blower diatur kecepatannya masing-masing untuk aliran primer $10 \mathrm{~m} / \mathrm{s}$ dan aliran sekunder $17 \mathrm{~m} / \mathrm{s}$. Setelah mencapai kondisi steady state, bahan bakar sekam padi dengan jumlah 600 gram dimasukkan kedalam reaktor gasifikasi melalui fuel feeder kemudian motor listrik dinyalakan agar bahan bakar sekam padi yang masuk ke reaktor gasifikasi masuk secara konstan. Catat waktu mulai menyala dan lama nyala apinya. Setelah dilakukan penelitian diperoleh data berupa massa input, massa output, lama nyala dan waktu operasi dari reaktor. Waktu operasi adalah durasi lamanya proses percobaan gasifikasi dari awal memasukkan bahan bakar hingga sampai terciptanya gas mampu bakar hasil gasifikasi. Lakukan pengujian sebanyak tiga kali dengan variasi temperatur pada reaktor gasifikasi yaitu $600^{\circ} \mathrm{C}, 650^{\circ} \mathrm{C}$ dan $700^{\circ} \mathrm{C}$.

\subsection{Fuel Conversion Rate (FCR)}

Fuel conversion rate adalah laju konversi bahan bakar padat menjadi gas atau jumlah konversi bahan bakar per satuan waktu. Perkiraan kecepatan bahan bakar yang dikonversi, dapat dihitung dengan persamaan berikut:

$$
\text { Fuel Conversion Rate }=\frac{V_{b b}}{F_{g}}
$$

Dimana : $\quad \mathrm{V}_{\mathrm{bb}}=$ Laju masuk bahan bakar.

$\mathrm{F}_{\mathrm{g}}=$ Faktor gasifikasi (asumsi waktu proses gasifikasi terhadap waktu pemasukan bahan bakar yang disesuaikan dengan jumlah bahan bakar yang digunakan).

Bahan bakar yang dikonversi pada proses gasifikasi dapat dihitung menggunakan rumus:

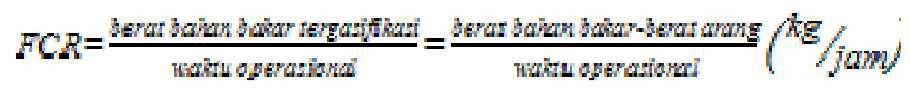

Waktu operasional adalah durasi lama proses percobaan gasifikasi dari awal memasukkan bahan bakar hingga sampai terciptanya gas mampu bakar.

\section{HASIL DAN PEMBAHASAN}

\subsection{Hasil Penelitian}

Setelah dilakukan penelitian diperoleh data berupa massa input, massa output, lama nyala dan waktu operasi dari reaktor.. Data penelitian tersebut dapat dilihat pada tabel 4 .

Tabel 4. Data hasil penelitian variasi temperatur reaktor gasifikasi

\begin{tabular}{cccccc}
\hline $\begin{array}{c}\text { Variasi } \\
\text { Temperatur } \\
\left({ }^{\mathbf{0}} \mathbf{C}\right)\end{array}$ & $\begin{array}{c}\text { Massa } \\
\text { Input } \\
\text { (gram) }\end{array}$ & $\begin{array}{c}\text { Massa } \\
\text { Output } \\
\text { (gram) }\end{array}$ & $\begin{array}{c}\text { Waktu } \\
\text { Mulai } \\
\text { Menyala } \\
\text { (detik) }\end{array}$ & $\begin{array}{c}\text { Waktu } \\
\text { Lama } \\
\text { Nyala } \\
\text { (detik) }\end{array}$ & $\begin{array}{c}\text { Waktu } \\
\text { Operasi } \\
\text { (detik) }\end{array}$ \\
\hline $\begin{array}{c}\text { Variasi I } \\
(600)\end{array}$ & 600 & 160 & 30 & 250 & 280 \\
$\begin{array}{c}\text { Variasi II } \\
(650)\end{array}$ & 600 & 134 & 22 & 262 & 284 \\
$\begin{array}{c}\text { Variasi III } \\
(700)\end{array}$ & 600 & 121 & 17 & 274 & 291 \\
\hline
\end{tabular}

Fuel conversion rate dari masing-masing variasi temperatur reaktor gasifikasi dapat dihitung menggunakan persamaan 2. Setelah dilakukan perhitungan data, nilai fuel conversion rate masing-masing variasi temperatur reaktor gasifikasi dapat dilihat pada tabel 5 . 
Jurnal METTEK Volume 4 No 2 (2018) pp 37 - 42

ojs.unud.ac.id/index.php/mettek

Tabel 5. Fuel conversion rate dari masing-masing variasi temperatur reaktor gasifikasi

\begin{tabular}{cccc}
\hline $\begin{array}{c}\text { Variasi } \\
\text { Temperatur } \\
\left({ }^{\circ} \mathbf{C}\right)\end{array}$ & $\begin{array}{c}\text { Jumlah bahan } \\
\text { bakar } \\
(\mathbf{K g})\end{array}$ & $\begin{array}{c}\text { Waktu } \\
\text { operasi } \\
(\mathbf{J a m})\end{array}$ & $\begin{array}{c}\text { Fuel Conversion Rate } \\
\text { (Kg/Jam) }\end{array}$ \\
\hline $\begin{array}{c}\text { Variasi I } \\
(600)\end{array}$ & 0.6 & 0.078 & 5.657 \\
$\begin{array}{c}\text { Variasi II } \\
(650)\end{array}$ & 0.6 & 0.079 & 5.907 \\
$\begin{array}{c}\text { Variasi III } \\
(700)\end{array}$ & 0.6 & 0.081 & 5.926 \\
\hline
\end{tabular}

Dari perhitungan fuel conversion rate pada setiap variasi temperatur reaktor gasifikasi dapat dianalisis dan dibuat grafik pengaruh variasi temperatur terhadap fuel conversion rate.

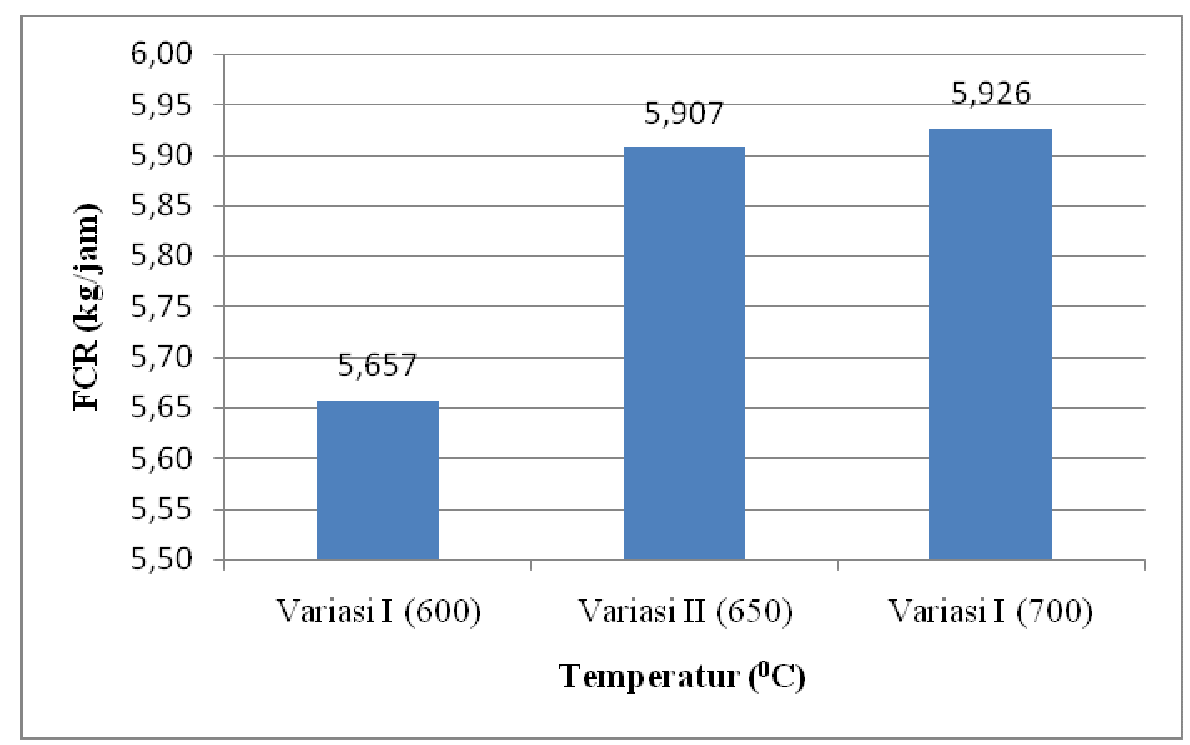

Gambar 2. Grafik pengaruh variasi temperatur terhadap fuel conversion rate bahan bakar

\subsection{Pengaruh Variasi Temperatur Terhadap Fuel Conversion Rate Bahan Bakar}

Pada proses gasifikasi terjadi reaksi-reaksi kimia sebagai berikut [1]:

Proses Oksidasi Partial

$\mathrm{C}+\frac{1}{2} \mathrm{O}_{2} \rightarrow \mathrm{CO}-111 \mathrm{~kJ} / \mathrm{mol}$

Proses Oksidasi Total

$\mathrm{C}+\mathrm{O}_{2} \rightarrow \mathrm{CO}_{2}-394 \mathrm{~kJ} / \mathrm{mol}$

Boudouard Reaction

$\mathrm{C}+\mathrm{CO}_{2} \rightarrow 2 \mathrm{CO}+172 \mathrm{~kJ} / \mathrm{mol}$

Water-Gas Reaction

$\mathrm{C}+\mathrm{H}_{2} \mathrm{O} \rightarrow \mathrm{CO}+\mathrm{H}_{2}+131 \mathrm{~kJ} / \mathrm{mol}$

Water-Gas Shift Reaction

$\mathrm{CO}+\mathrm{H}_{2} \mathrm{O} \rightarrow \mathrm{CO}_{2}+\mathrm{H}_{2}-41.2 \mathrm{~kJ} / \mathrm{mol}$

Methane Reaction

$\mathrm{C}+2 \mathrm{H}_{2} \rightarrow \mathrm{CH}_{4}-74.8 \mathrm{~kJ} / \mathrm{mol}$

Steam Reforming

$\mathrm{CH}_{4}+\mathrm{H}_{2} \mathrm{O} \rightarrow \mathrm{CO}+3 \mathrm{H}_{2}+206.2 \mathrm{~kJ} / \mathrm{mol}$

Dry Reforming

$\mathrm{CH}_{4}+\mathrm{CO}_{2} \rightarrow 2 \mathrm{CO}+2 \mathrm{H}_{2}+247.4 \mathrm{~kJ} / \mathrm{mol}$ 
Peningkatan temperatur pada reaktor gasifikasi menyebabkan meningkatnya reaksi endotermik baik secara heterogen maupun homogen seperti Boudouard Reaction (R3) dan Water-Gas Reaction (R4) dimana pada temperatur tinggi kandungan karbon pada bahan bakar cenderung bereaksi dengan $\mathrm{CO}_{2}$ dan uap air [5]. Reaksi endotermik lainnya yang terjadi adalah Steam Reforming (R7) yaitu reaksi antara $\mathrm{CH}_{4}$ dengan $\mathrm{H}_{2} \mathrm{O}$ dan Dry Reforming (R8) yaitu reaksi antara $\mathrm{CH}_{4}$ dengan $\mathrm{CO}_{2}$ [6]. Peningkatan reaksi-reaksi ini menyebabkan bahan bakar sekam padi yang dimasukkan ke reaktor gasifikasi akan lebih cepat menghasilkan gas mampu bakar dimana bisa dilihat dari waktu menyalanya api yang lebih cepat, lamanya api menyala lebih lama dan juga sisa arang yang masih tersisa setelah proses gasifikasi semakin sedikit, dengan kata lain fuel conversion rate atau laju dari konversi bahan bakar pun akan meningkat. Grafik pada gambar 2 menunjukkan bahwa nilai fuel conversion rate akan meningkat seiring dengan meningkatnya temperatur dari reaktor gasifikasi. Fuel conversion rate dari bahan bakar sekam padi tertinggi diperoleh pada variasi III $\left(700^{0} \mathrm{C}\right)$ yaitu 5.926 $\mathrm{Kg} / \mathrm{jam}$ dan terendah pada variasi I $\left(600^{\circ} \mathrm{C}\right)$ yaitu $5.657 \mathrm{Kg} / \mathrm{jam}$. Ini dikarenakan dengan meningkatnya temperatur maka reaksi-reaksi yang terjadi pada proses gasifikasi maupun pembakaran akan meningkat. Temperatur yang meningkat pada reaktor gasifikasi mendorong aktivitas reaksi endotermik meningkat sehingga bahan bakar akan lebih cepat bereaksi dan menghasilkan producer gas.

\section{SIMPULAN}

Semakin tinggi temperatur pada reaktor gasifikasi maka performansi gasifikasi berupa fuel conversion rate semakin meningkat, temperatur yang meningkat pada reaktor gasifikasi mendorong aktivitas reaksi endotermik meningkat sehingga bahan bakar akan lebih cepat bereaksi dan menghasilkan producer gas.

\section{DAFTAR PUSTAKA}

[1] Basu, Prabir. 2013. Biomassa Gasification, Pyrolisis and Torefaction Practical Design. Second Edition, USA: Elsevier Inc.

[2] Wang, L.Q., Chen, Z.S., 2013. Gas Generation by Co-gasification of Biomass and Coal in an Autothermal Fluidized Bed Gasifier. Applied Thermal Engineering, 59: $278-282$.

[3] Goransson, Soderlind, Jie He, Zhang. 2011. Review of Syngas Production via Biomass DFBGs. Renewable and Sustainable Energy Reviews, 15: 482-492.

[4] Rodrigues, Almeida, Ribeiro, Neto, Ramalho, Pilao. 2017. Influence of Temperature on The Gasification of Cork Wastes. Energy Procedia, 136: 127-132.

[5] Fermoso J, Arias B, Plaza MG, Pevida C, Rubiera F, Pis JJ, et al. 2009. High-pressure CO-gasification of Coal with Biomass and Petroleum Coke. Fuel Processing Technology, 90: 926-932.

[6] Doherty W, Reynolds A, Kennedy D. 2009. The Effect of Air Preheating in a Biomass CFB Gasifier Using ASPEN Plus Simulation. Biomass Bioenergy, 33: 1158-1167. 